\title{
PENGETAHUAN DAN DUKUNGAN SUAMI TERHADAP KEIKUTSERTAAN PASANGAN USIA SUBUR PADA SCREENING KANKER LEHER RAHIM DI WILAYAH KERJA PUSKESMAS TIPO
}

\section{Husband's Knowledge and Support Towards Participation of Fertile Age Couples For Cervical Cancer Screening in Tipo Community Health Center}

\author{
Sri Restu Tempali \\ Poltekkes Kemenkes Palu \\ (restutempali@gmail.com HP:085241154645)
}

\begin{abstract}
ABSTRAK
Pencegahan kanker leher rahim dapat dilakukan dengan melakukan screening melalui pemeriksaan Inspeksi Visual Asam Asetat (IVA). Namun, pemeriksaan IVA di Puskesmas Tipo tahun 2017 masih rendah, yaitu hanya 72 jiwa dari 1.513 jiwa Pasangan Usia Subur (PUS). Penelitian ini bertujuan untuk mengetahui hubungan pengetahuan dan dukungan suami terhadap keikutsertaan pasangan usia subur untuk screening kanker leher rahim. Desain penelitian ini menggunakan Cross Sectional dengan populasi semua PUS umur 15-49 tahun yang datang berkunjungan ke wilayah kerja Puskesmas Tipo. Adapun sampel sebanyak 54 responden dengan teknik Purposive sampling. Data penelitian dianalisis dengan uji Fisher's exact. Hasil penelitian menunjukkan bahwa tidak ada hubungan yang signifikan antara pengetahuan $(\mathrm{p}=0,202)$ dan keikutsertaan PUS pada Screening kanker leher rahim. Sedangkan, hasil yang lain menunjukkan ada hubungan yang signifikan antara dukungan suami $(p=0,023)$ dengan keikutsertaan PUS pada Screening kanker leher rahim. Kesimpulan, terdapat hubungan yang signifikan antara dukungan suami dengan keikutsertaan PUS pada Screening kanker leher rahim di Wilayah Kerja Puskesmas Tipo. Bidan diharapkan dapat melibatkan suami dalam sosialisasi pentingnya pemeriksaan IVA kepada PUS.
\end{abstract}

Kata kunci : Pengetahuan, dukungan suami, screening kanker leher rahim

\section{ABSTRACT}

Prevention of cervical cancer can be done by screening through an inspection of Visual Acetate Acid (IVA). However, the IVA examination at Tipo Community Health Center in 2017 is still low, which is only 72 people out of 1,513 people of Fertile Age Couples (PUS). This study aims to determine the relationship between husband's knowledge and support towards the participation of fertile age couples for cervical cancer screening. The design of this study used Cross Sectional with a population of all PUS aged 15-49 years who came to visit the working area of Tipo Community Health Center. The sample are 54 respondents with Purposive sampling technique. The research data was analyzed by Fisher's exact test. The results showed that there was no significant relationship between knowledge $(p=0.202)$ and the participation of PUS in cervical cancer screening. Whereas, the other results showed that there was a significant relationship between husband's support $(p=0.023)$ and the participation of the PUS for cervical cancer screening. Conclusions, there is a significant relationship between husband's support and the participation of Fertile Age Couples in cervical cancer Screening in the Work Area of Tipo Health Center. Midwives are expected to be able to involve the husband in the socialization event of the importance of IVA examination to PUS

Keywords : Husband's Knowledge, Support, Cervical Cancer Screening 


\section{PENDAHULUAN}

Kanker leher rahim merupakan tumor ganas yang tumbuh di dalam leher rahim pada bagian terendah dari rahim yang menempel di puncak vagina. Penyebab terbesar kanker leher rahim adalah infeksi Human Pappiloma Virus (HPV) yang menular lewat hubungan seksual $^{(1)}$. World Health Organization mencatat, setiap tahun sekitar 15.000 kasus kanker leher rahim ditemukan di Indonesia, laporan dari 13 pusat patologi di Indonesia juga menunjukkan bahwa kanker leher rahim masih merupakan kanker dengan frekuensi tertinggi yaitu $36 \%$ dari seluruh wanita di Indonesia $^{(2)}$. Data Global Burden Cancer menyatakan $80 \%$ kasus kanker leher rahim saat ini ada di negara ke tiga atau negara berkembang, tiap hari dari 40 perempuan yang terdiagnosa kanker leher rahim dan 20 diantaranya meninggal dunia ${ }^{(3)}$. Tingginya kejadian kanker leher rahim di Indonesia tersebut merupakan angka kejadian kanker leher rahim tertinggi di dunia $^{(4)}$

Kanker leher rahim berkembang disebabkan karena rendahnya cakupan screening kanker leher rahim. Program screening di Indonesia masih kurang dari 5\%. Penderita kanker leher rahim pada umumnya akan datang ketika sudah stadium lanjut, hal ini terjadi karena kanker leher rahim biasanya tidak menimbulkan gejala awal yang jelas, tetapi bisa disembuhkan jika ditemukan secara dini dengan melakukan screening atau deteksi $\operatorname{dini}^{(5)}$.

Pemeriksaan atau tes yang dilakukan pada orang yang belum menunjukkan adanya gejala penyakit untuk menemukan penyakit yang belum terlihat atau masih berada pada stadium praklinik $^{(6)}$. Cakupan screening yang efektif dalam menurunkan angka kesakitan dan angka kematian karena kanker leher rahim adalah $85 \%$. Program pemerintah mengenai screening kanker leher rahim tercantum dalam Kepmenkes RI Nomor 796/Menkes/SK/VII/ 2010 tentang pedoman teknis pengendalian kanker payudara dan kanker leher rahim. Pemeriksaan Inspeksi Visual Asam Asetat (IVA). Pemeriksaan IVA merupakan salah satu metode screening kanker leher rahim yang efektif digunakan di negara berkembang ${ }^{(8)}$.

Angka kejadian kanker leher rahim di Sulawesi Tengah yaitu 183 kasus. Cakupan screening IVA hanya $2,36 \%$, dimana angka tersebut masih sangat rendah dari target yang akan dicapai tahun 2015, yaitu sebesar $10 \%$. Pemeriksaan IVA pada 10.986 WUS dengan hasil pemeriksaan IVA positif sebanyak 370 jiwa dan kanker leher rahim berjumlah 10 jiwa. Kota Palu tertinggi kasus kanker leher rahim sebanyak 6 orang dari 13 Kabupaten/Kota lainnya ${ }^{(9)}$.

Puskesmas di Kota Palu yang telah melakukan program IVA adalah Puskesmas Sangurara, Puskesmas Singgani dan Puskesmas Kamonji. Sebaliknya puskesmas yang paling rendah melakukan pemeriksaan IVA adalah Puskesmas Tipo ${ }^{(10)}$. Data dari Puskesmas Tipo yang melakukan pemeriksaan IVA tahun 2015 berjumlah 159 orang dan mengalami penurunan pada tahun 2016 yaitu, hanya 
berjumlah 72 orang. Berdasarkan hasil wawancara pendahuluan peneliti dengan bidan yang menjadi kordinator pemeriksaan IVA rendahnya cakupan screening kanker leher rahim melalui pemeriksaan IVA disebabkan oleh pengetahuan dan kesadaran masyarakat yang kurang tentang screening kanker leher rahim, rasa malu dan takut untuk memeriksakan organ reproduksinya, meskipun penyuluhan tentang screening IVA sering dilakukan di posyandu atau posbindu ${ }^{(11)}$.

Suami yang mendukung istrinya melakukan IVA dapat menjadi pendorong bagi seorang wanita untuk berpartisipasi dalam pemeriksaan IVA Hal ini sebagai keikutsertaan PUS dengan screening kanker leher rahim menggunakan metode $\operatorname{IVA}^{(5)}$. Penelitian Meliasari (2015) menunjukkan ada hubungan yang signifikan antara pengetahuan dan tindakan pemeriksaan IVA serta dukungan suami $(\mathrm{p}=0,00)^{(11)}$.

\section{METODE PENELITIAN}

Penelitian analitik dengan rancangan penelitian Cross Sectional. Populasi dalam adalah semua pasangan usia subur dengan umur 15-49 tahun yang datang berkunjung ke wilayah kerja Puskesmas Tipo. Pengambilan sampel dilakukan dengan tehnik purposive sampling dengan jumlah sampel sebanyak 49 orang. Penelitian dilaksanakan pada tanggal 15 Mei - 5 Juni tahun 2018 di wilayah kerja Puskesmas Tipo.

\section{HASIL}

Responden yang berumur 20-35 tahun berjumlah 44 responden $(89,8 \%)$ pendidikan tertinggi pada kelompok SMP berjumlah 34 responden (69.4\%). Responden yang memiliki pengetahuan dengan kategori kurang $(36,7 \%)$ dan kategori baik $(63,2 \%)$. Ibu yang tidak mendapat dukungan suami $(75,5 \%)$ dan ibu yang mendapat dukungan suami $(24,4 \%)$.

Tabel 1. Karakteristik Responden Berdasarkan Umur dan Pendidikan di Wilayah Kerja Puskesmas Tipo

\begin{tabular}{ccc}
\hline \multicolumn{1}{c}{ Variabel } & f & \% \\
\hline Umur & & \\
$<20$ tahun & 1 & 2,0 \\
20-35 tahun & 44 & 89,8 \\
$>35$ tahun & 4 & 8,2 \\
Pendidikan & & \\
SD & 1 & 2,0 \\
SMP & 34 & 69,4 \\
SLTA & 12 & 24,5 \\
Diploma/PT & 2 & 4,1 \\
\hline Sumber $:$ Data Primer, 2018 & &
\end{tabular}

Sumber : Data Primer, 2018

Tabel 2. Distribusi Frekuensi Responden berdasarkan pengetahuan dan dukungan suami di Wilayah Kerja Puskesmas Tipo

\begin{tabular}{lcc}
\hline \multicolumn{1}{c}{ Variabel } & f & \% \\
\hline Pengetahuan & & \\
Baik & 31 & 63,3 \\
Kurang Baik & 18 & 36,7 \\
Dukungan Suami & & \\
Mendukung & 12 & 24,5 \\
Tidak Mendukung & 37 & 75,5 \\
\hline & 49 & 100,0 \\
\hline Sumber : Data Primer, 2018 & &
\end{tabular}

Sumber : Data Primer, 2018

Tabel 3. Distribusi Frekuensi Responden berdasarkan keikutsertaan PUS Screening kanker leher rahim di Wilayah Kerja Puskesmas Tipo

\begin{tabular}{ccc}
\hline $\begin{array}{c}\text { Keikutsertaan PUS } \\
\text { screening kanker leher } \\
\text { rahim }\end{array}$ & f & \% \\
\hline Ya & 14 & 28,6 \\
Tidak & 35 & 71,4 \\
\hline & 49 & 100,0 \\
\hline
\end{tabular}

Sumber : Data Primer, 2018 
Tabel 4. Hubungan Pengetahuan dan Dukungan Suami dengan Keikutsertaan Pasangan Usia Subur (PUS) Screening Kanker Leher Rahim di Puskesmas Tipo

\begin{tabular}{|c|c|c|c|c|c|c|}
\hline \multirow{3}{*}{ Variabel } & \multicolumn{4}{|c|}{$\begin{array}{c}\text { Keikutsertaan Screening Kanker } \\
\text { Leher Rahim }\end{array}$} & \multirow[t]{3}{*}{ Total } & \multirow[t]{3}{*}{$\rho$-value } \\
\hline & \multicolumn{2}{|c|}{ Tidak } & \multicolumn{2}{|c|}{ Ya } & & \\
\hline & $\mathbf{f}$ & $\%$ & $\mathbf{f}$ & $\%$ & & \\
\hline \multicolumn{7}{|l|}{ Pengetahuan } \\
\hline Kurang & 15 & 83,3 & 3 & 16,6 & 18 & \multirow{2}{*}{0,202} \\
\hline Baik & 20 & 64,5 & 11 & 35,4 & 31 & \\
\hline \multicolumn{7}{|l|}{ Dukungan Suami } \\
\hline Tidak Mendukung & 30 & 81 & 7 & 19 & 37 & \multirow{2}{*}{0,023} \\
\hline Mendukung & 5 & 41,7 & 7 & 58,3 & 12 & \\
\hline
\end{tabular}

Sumber : Data Primer, 2018.

Berdasarkan Tabel 4 hubungan pengetahuan dengan keikutsertaan PUS dengan screening kanker leher rahim, yaitu pasangan usia subur yang berpengetahuan kurang berjumlah 18 orang, yang tidak pernah melakukan pemeriksaan IVA berjumlah 15 orang $(83,3 \%)$ dan yang pernah melakukan pemeriksaan IVA berjumlah 3 orang $(16,6 \%)$. PUS yang berpengetahuan baik berjumlah 31 orang, yang tidak pernah melakukan pemeriksaan IVA berjumlah 20 orang $(64,5 \%)$ dan yang pernah melakukan pemeriksaan IVA berjumlah 11 orang $(35,4 \%)$. Hasil uji fisher's exact didapatkan nilai $\mathrm{p}$-value $=0,202$ $(0,202>0,05)$ artinya bahwa tidak terdapat hubungan yang signifikan antara pengetahuan dengan keikutsertaan PUS Screening kanker leher rahim.

Hubungan dukungan suami dengan keikutsertaan PUS screening kanker leher rahim menunjukkan ibu yang tidak mendapat dukungan suami berjumlah 37 orang, yang tidak pernah melakukan pemeriksaan IVA berjumlah 30 orang $(81 \%)$ dan yang pernah melakukan pemeriksaan IVA berjumlah 7 orang (19\%). Ibu PUS yang mendapat dukungan suami berjumlah 12 orang, yang tidak permah melakukan pemeriksaan IVA berjumlah 5 orang $(41,7 \%)$ dan ibu yang pernah melakukan pemeriksaan IVA berjumlah 7 orang $(58,3 \%)$. Hasil uji fisher's exact didapatkan nilai $\mathrm{p}$-value $=0,023$ $(0,023<0,05)$ artinya bahwa terdapat hubungan yang signifikan antara pengetahuan dengan keikutsertaan PUS Screening kanker leher rahim.

\section{PEMBAHASAN}

Pada penelitian ini, diantara 49 orang responden terdapat 31 orang yang berpengetahuan baik dan 18 orang berpengetahuan kurang. Sebanyak 14 orang yang pernah melakukan pemeriksaan IVA terdapat $(35,4 \%)$ yang berpengetahuan baik dan $(16,6 \%)$ yang berpengetahuan kurang. Berdasarkan hasil uji fisher's exact didapatkan bahwa tidak terdapat hubungan yang signifikan antara pengetahuan dengan keikutsertaan PUS screening kanker leher rahim $(\mathrm{p}=0,202)$.

Hasil penelitian ini tidak sesuai dengan teori yang dikemukakan oleh Ariani bahwa pengetahuan merupakan salah satu faktor yang 
mempengaruhi terbentuknya sikap seseorang. Berdasarkan pengalaman dan penelitian, jika seseorang memiliki pengetahuan yang baik maka akan memiliki perilaku yang baik pula $^{(12)}$. Demikian pula hasil Silfia dan Muliati yang menyatakan bahwa terdapat hubungan yang signifikan antara pengetahuan dengan pemeriksan IVA di Puskesmas Talise Palu $(\mathrm{p}=0,027)^{(13)}$.

Namun, hasil penelitian ini sejalan dengan hasil penelitian yang dilakukan Suryandari di Kecamatan Purwokerto Timur Kabupaten Banyumas yang menyatakan bahwa tidak terdapat hubungan antara pengetahuan dengan keikutsertaan WUS dalam penapisan tes IVA $(\mathrm{p}=0,177)^{(14)}$. Penelitian ini juga sejalan dengan hasil penelitian yang dilakukan oleh Febriani di Kecamatan Gisting Kabupaten Tanggamus Lampung yang menyatakan bahwa tidak terdapat hubungan yang signifikan antara pengetahuan dengan deteksi dini kanker serviks $(\mathrm{p}=0,357)^{(15)}$.

Hubungan dukungan suami dengan keikutsertaan PUS screening kanker leher rahim. Pada penelitian ini, terdapat 12 orang yang mendapat dukungan suami dan 37 orang yang tidak mendapat dukungan suami. Dari 12 orang yang mendapat dukungan suami hanya 7 orang $(58,3 \%)$ yang pernah melakukan pemeriksaan IVA, 5 orang $(41,7 \%)$ yang tidak pernah melakukan pemeriksaan IVA dan 7 orang (19\%) yang pernah melakukan pemeriksaan IVA tetapi tidak mendapat dukungan suami serta 30 orang $(81 \%)$ yang tidak pernah melakukan pemeriksaan IVA dan tidak mendapat dukungan suami. Berdasarkan hasil uji fisher's exact didapatkan bahwa terdapat hubungan yang signifikan antara dukungan suami dengan keikutsertaan PUS screening kanker leher rahim $(\mathrm{p}=0,023)$. Hasil penelitian ini menunjukkan bahwa dukungan suami sangat berperan penting bagi keikutsertaan ibu PUS untuk screening kanker leher rahim, karena suami sebagai kepala keluarga yang memberikan persetujuan dan dorongan dalam keikutsertaan ibu PUS dengan screening kanker leher rahim.

Hasil penelitian ini juga sejalan dengan penelitian yang dilakukan oleh Meliasari yang menyatakan bahwa terdapat hubungan yang signifikan antara dukungan suami dengan pemeriksaan IVA $(\mathrm{p}=0,000<0,05)^{(11)}$ dan juga sejalan dengan penelitian yag dilakukan oleh Suyami di Klaten yang menyatakan bahwa terdapat hubungan yang signifikan antara dukungan suami dengan partisipasi pemeriksaan IVA pada ibu wanita usia subur $(p=0,014<0,05)^{(16)}$. Sejalan dengan penelitian Wahyuni (2013) dalam Suyami (2017) yang mengatakan bahwa dukungan suami sebagai faktor penetu untuk memberi dorongan pada istri karena terus-menerus berperan penting dalam membantu anggotanya mempelajari cara-cara baru untuk hidup lebih sehat, menurunkan rasa takut terhadap kenyatan hasil pemeriksaan kesehatan yang akan dihadapi, dan mengembalikan rasa percaya diri pada istri jika mengalami masalah kesehatan pada istri. 


\section{KESIMPULAN DAN SARAN}

\begin{abstract}
Tidak terdapat hubungan yang signifikan antara pengetahuan dengan keikutsertaan PUS screening kanker leher rahim dan Terdapat hubungan yang signifikan antara dukungan suami dengan keikutsertaan PUS screening kanker leher rahim. Diharapkan dapat dijadikan tolak ukur bagi Puskesmas Tipo untuk mensosialisasikan pentingnya screening kanker leher rahim secara menyeluruh diwilayah kerja Puskesmas Tipo, sehingga mampu meningkatkan pengetahuan dan kesadaran Pasangan Usia Subur (PUS)
\end{abstract} tentang pentingnya melakukan screening kanker leher rahim.

\section{UCAPAN TERIMA KASIH}

Terima kasih kepada 1) Direktur Poltekkes Kemenkes Palu, 2) Kepala Dinas kesehatan dan Kepala Puskesmas Tipo, 3) para responden penelitian.

\section{DAFTAR PUSTAKA}

1. Purwono J, Sari SD. Efektifitas Penyuluhan Kesehatan Terhadap Pengetahuan Ibu Tentang Kanker Serviks. Wacana Kesehatan. 2017;2(1). http://jurnal.akperdharmawacana.ac.id

2. Pratiwi AM. Riwayat Mendapat Konseling Tentang IVA Berhubungan Dengan Keikutsertaan IVA Pada Wanita Usia Subur Di Puskesmas Sedayu I Dan Sedayu II Bantul. 2016;4(1) ejournal.almaata.ac.id

3. Ridarti, Gita. Gambaran Pengetahuan Dan Dukungan Suami Tentang Pemeriksaan Pap Smear Pada Pasangan Usia Subur Di Desa Sungai Cemara Kecamatan Sadu Kabupaten Tanjung Jabun Timur Tahun 2014. Scientia Journal 2015 4(1).

4. Anggraini FD. Faktor Yang Mempengaruhi Impelentasi Program Deteksi Dini Kanker Serviks Melalui Pemeriksaan IVA Di Puskesmas Wilayah Kota Surabaya. Jurnal Ilmiah Kesehatan 2015;8(1) http://journal.unusa.ac.ids
5. Anggraeni FD, Benedikta K. Dukungan Suami Terhadap Deteksi Dini Kanker Serviks Pada Pasangan Usia Subur (PUS) Di Dusun Ngasem Desa Timbulharjo Sewon Bantul Tahun 2016. Media Ilmu Kesehatan 2016;5(3) http://ejournal.stikesayaniyk.ac.id

6. Basuki D, Puspita A, Hasil Skrining Metode Pemeriksaan Inspeksi Visual Asam Asetat (IVA) Pada Wanita Usia Subur Di Puskesmas Blooto Dalam Upaya Pencegahan Kanker Cerviks Kota Mojokerto, 2014.

7. Taufia D, Faktor-Faktor Yang Berhubungan Dengan Perilaku Wanita Pasangan Usia Subur (PUS) Dalam Deteksi Dini Kanker Leher Rahim Metode IVA Di Wilayah Kerja Puskesmas Nanggalo Padang Tahun 2017. Skripsi. Jurusan Kebidanan, Politeknik Kesehatan Kemenkes Padang, 2017. poltekkestjk.ac.id

8. Marbun U, Analisis Peningkatan Pengetahuan Dan Sikap Pasangan Usia Subur Dalam Melakukan Pemeriksaan IVA Di Desa Bowong Cindea Kabupaten Pangkep Tahun 2016. Jurnal Kebidanan Vokasional ejournal.stikesnh.ac.id

9. Dinas Kesehatan Provinsi Sulawesi Tengah. 2015-2016. Profil Dinas Kesehatan Provinsi Sulawesi Tengah

10. Dinas Kesehatan Kota Palu. 2015-2016. Profil Dinas Kesehatan Kota Palu

11. Meliasari D. Pengetahuan Dan Dukungan Suami Berhubungan Dengan Tindakan Pemeriksaan IVA Pada Pasangan Usia Subur di Desa Sunggal Kanan Tahun 2014. Panmed 2015;9(3).

12. Ariani AP. Aplikasi Metodologi Penelitian Kebidanan Dan Kesehatan Reproduksi. Nuha Medika: 2014. Yogyakarta.

13. Silfia NN, Muliati T. Hubungan Karakteristik, Pengetahuan dan Sikap Dengan Pemeriksaan Inspeksi Visual Asam Asetat (IVA) Pada Ibu Pasangan Usia Subur Di Puskesmas Talise. Caring 2017;1(2).

14. Suryandari AE. Hubungan Pengetahuan, Fatalisme, Kanker Dan Kesadaran Wanita Usia Subur (WUS) dalam penapisan Tes IVA. Kesmasindo 2014;6(3)

15. Febriani CA. Faktor-Faktor Yang Berhubungan Dengan Deteksi Dini Kanker Leher Rahim Di Kecamatan Gisting Kabupaten Tanggamus Lampung. Jurnal Kesehatan 2016;7(2).

16. Suyami. Dampak Dukungan Suami Terhadap Partisipasi Pemeriksaan Inpeksi Visual Asam Asetat (IVA) Pada Ibu Usia Subur Di Puskesmas Trucuk II Klaten. 2017 ejournal.stikesmukla.ac.id 